bad news, safeguarding cases, discussions about developmental delay to parents and adoption cases.

We noted that only $23 \%$ of trainees have received some form of training as simulation instructors.

From our survey, we also noted reluctance from some trainees regarding the use of simulation in community teaching.

Conclusion From our study, we have noted that the majority of trainees wish to integrate simulation as part of their community training. Making this a valuable learning exercise for them will require putting in place a robust simulation instruction programme. We are currently in discussion with simulation educators at the University of Hertfordshire to move this programme forwards.

\section{G105(P) SCREENING FOR MENTAL HEALTH CONDITIONS IN CHILDREN WITH EPILEPSY}

${ }^{1} \mathrm{~B}$ Wilkes, ${ }^{2} \mathrm{~S}$ Walsh, ${ }^{1} \mathrm{~A}$ Chryssanthakis, ${ }^{3} \mathrm{O}$ Tame, ${ }^{1} \mathrm{M}$ McGowan, ${ }^{2} \mathrm{G}$ Colville, II Hadjikoumi. 'Paediatric Epilepsy Service, St George's University Hospital, London, UK; ${ }^{2}$ Paediatric Clinical Psychology, St George's University Hospital, London, UK; ${ }^{3}$ St George's Medical School, St George's University of London, London, UK

\subsection{6/archdischild-2018-repch.102}

Background and aims There is a high burden of mental health $(\mathrm{MH})$ problems among children with epilepsy. The relationship between $\mathrm{MH}$ problems and epilepsy is bidirectional with shared risk factors. Our key aims were:

- To determine the prevalence of MH difficulties among the patients of our Secondary Paediatric Epilepsy Service.

- To ascertain if more input from MH services is required within the Secondary Paediatric Epilepsy Service.

- To demonstrate the use of a standardised behavioural screening questionnaire in assessing $\mathrm{MH}$ difficulties.

Methods The Strengths and Difficulites Questionnaire (SDQ) was used to screen for those at risk of, or currently experiencing $\mathrm{MH}$ problems. We received 86 replies and, following exclusions, 64 patients data was analysed. The patient's electronic notes were used to determine diagnoses and medications.

Results $56 \%$ of patients scored high or very high risk for having or developing $\mathrm{MH}$ difficulties. A chi- square test indicated a significant difference $(p<0.001)$ in the proportion of children with epilepsy with clinically significant scores versus the proportion in the community samples. Peer and pro-social subdomains scored in the 'high' risk category whilst the other subdomains scored in 'close to average' risk. Patients not on anti-epileptic drugs have close to average scores. There is trend towards those on more than 1 Antiepileptic drug having higher scores. Developmental disorder increases that risk of having a high or very high score from $43 \%$ to $68 \%$.

Conclusions Our results reflect similar prevalence to that demonstrated in the literature; children with epilepsy have a high risk of developing $\mathrm{MH}$ disorders. Our data highlights the need to improve identification, diagnosis, prevention and management of $\mathrm{MH}$ problems in children with epilepsy on both a national and local level.

\section{G106(P) TARGETED TECHNICAL SKILLS SIMULATION TRAINING HELPS PAEDIATRIC TRAINEES WITH COLLEGE CORE PROCEDURES}

${ }^{1} \mathrm{P}$ Mallett, ${ }^{1} \mathrm{C}$ Watterson, ${ }^{1} \mathrm{C}$ Junk, ${ }^{1} \mathrm{~T}$ Bourke, ${ }^{1} \mathrm{~A}$ Thompson, ${ }^{2} \mathrm{~S}$ Christie. ${ }^{1}$ Paediatric Simulation Education Department, Royal Belfast Hospital for Sick Children, Belfast, UK ${ }^{2}$ School of Paediatrics and Child Health, Northern Ireland Medical and Dental Training Agency, Belfast, UK

\subsection{6/archdischild-2018-rcpch.103}

Aims Acute Paediatrics is a stimulating and challenging training programme. The Royal College of Paediatrics and Child Health (RCPCH) provide a comprehensive curriculum for trainees during these years. In Level 1 Training (ST1-3), there are a number of core practical procedures trainees are expected to perform prior to progression to Level 2 training. These skills include Neonatal Intubation, Lumbar Puncture (LP) and Intraosseous (IO) Access. ${ }^{1}$

Often it may be difficult for trainees to gain significant experience in these skills and achieving competence can be challenging. Reasons for this include lack of opportunity, lack of experience, and low procedural confidence. The RCPCH advocates the delivery of Simulation and Technology Enhanced Learning (TEL) including in the area of technical skills training. ${ }^{2}$

By creating a technical skills simulation training day, we aimed to increase trainee exposure and confidence to core college procedures.

Methods We created a simulation training day for Level 1 Regional Training focused on 3 core procedures. We asked Paediatric ST1-3 trainees about previous teaching, experiences and confidence levels with these skills.

Results 24 ST1-3 trainees were surveyed. Prior to the teaching, $2(8 \%)$ trainees felt their Intubation skills were adequate, $12(50 \%)$ described their LP skills as satisfactory and $4(16 \%)$ trainees labelled their IO access skills as acceptable.

Following the training session, 23 of the 24 trainees (96\%) felt significantly more confident in approaching all 3 of the core practical skills. All 24 Trainees (100\%) felt that simulated practice helped improve their technical skills and all (100\%) felt it would be useful in their daily job.

Conclusion Simulation-based training for procedural skills has been shown to be effective for trainees and has been widely used in many training programs. ${ }^{3}$ By integrating this into the Deanery's Regional teaching programme, we have presented junior trainees the opportunity to gain vital hands-on experience on high-fidelity models, which has improved procedural exposure, enhanced user-confidence and may potentially develop procedural competence. We hope to extend this programme to higher level trainees and incorporate other core procedural skills in a bid to further promote a safe, traineefriendly, patient-centred simulated learning environment.

\section{REFERENCES}

1. Curriculum for Paediatric Training. General paediatrics: Level 1, 2 and 3 training August 2016. http://www.rcpch.ac.uk/training-examinations-professional-development/postgraduate-training/general-paediatrics-training/ge\#curriculum

2. Strategy- Simulation and TEL. Royal college of paediatrics and child health January 2015. http://www.rcpch.ac.uk/training-examinations-professional-development/ postgraduate-training/simulation-and-technology-enh

3. Barsuk JH, Cohen ER, et al. Simulation-based education with mastery learning improves residents' lumbar puncture skills. Neurology 2012;79(2):132-7. 